Supporting Information for

\title{
Is the Imidazolium Cation a Unique Promoter for Electrocatalytic Reduction of Carbon Dioxide?
}

\author{
Shu-Feng Zhao, ${ }^{\dagger}$ Mike Horne, ${ }^{* \dagger}$ Alan M. Bond ${ }^{\dagger}$ and Jie Zhang* ${ }^{\dagger}$ \\ ${ }^{\dagger}$ School of Chemistry and Australian Research Council Centre of Excellence for Electromaterials \\ Science, Monash University, Clayton, Victoria, 3800, Australia. \\ CSIRO Process Science and Engineering, Box 312, Clayton South, Victoria, 3168, Australia.
}




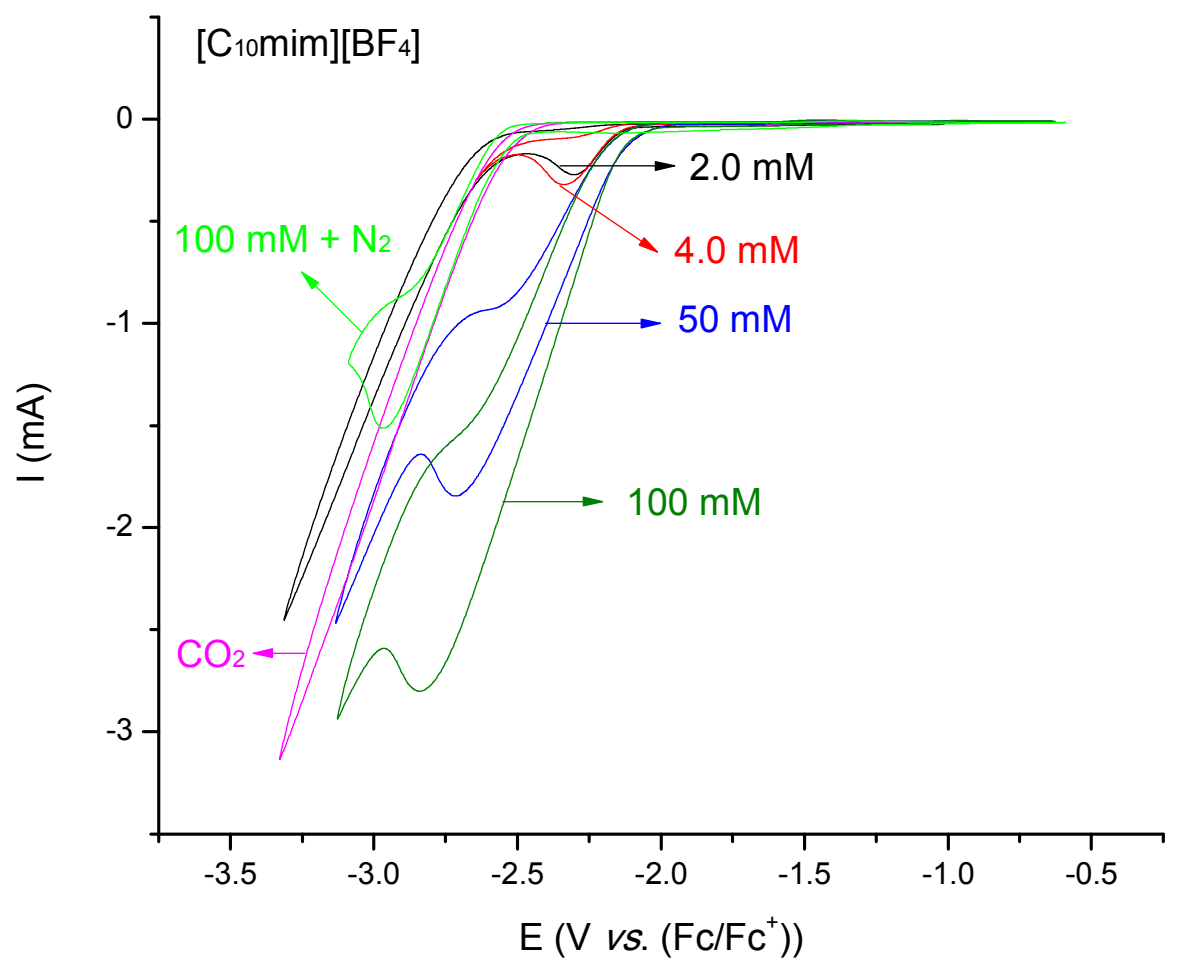

Figure S1. Cyclic voltammograms obtained with a $3.0 \mathrm{~mm}$ diameter Ag electrode at a scan rate of $0.1 \mathrm{~V} \mathrm{~s}^{-1}$ in $\mathrm{MeCN}\left(0.1 \mathrm{M} n-\mathrm{Bu}_{4} \mathrm{NPF}_{6}\right)$ and designated concentrations of $\left[\mathrm{C}_{10} \mathrm{mim}\right]\left[\mathrm{BF}_{4}\right](2.0 \mathrm{mM}(-), 4.0 \mathrm{mM}(-), 50.0 \mathrm{mM}(-)$ and $100.0 \mathrm{mM}(-))$ under a $\mathrm{CO}_{2}$ atmosphere and $100.0 \mathrm{mM}(-)$ under a $\mathrm{N}_{2}$ atmosphere. Cyclic voltammogram of $\mathrm{CO}_{2}(-)$ obtained under the same conditions. 


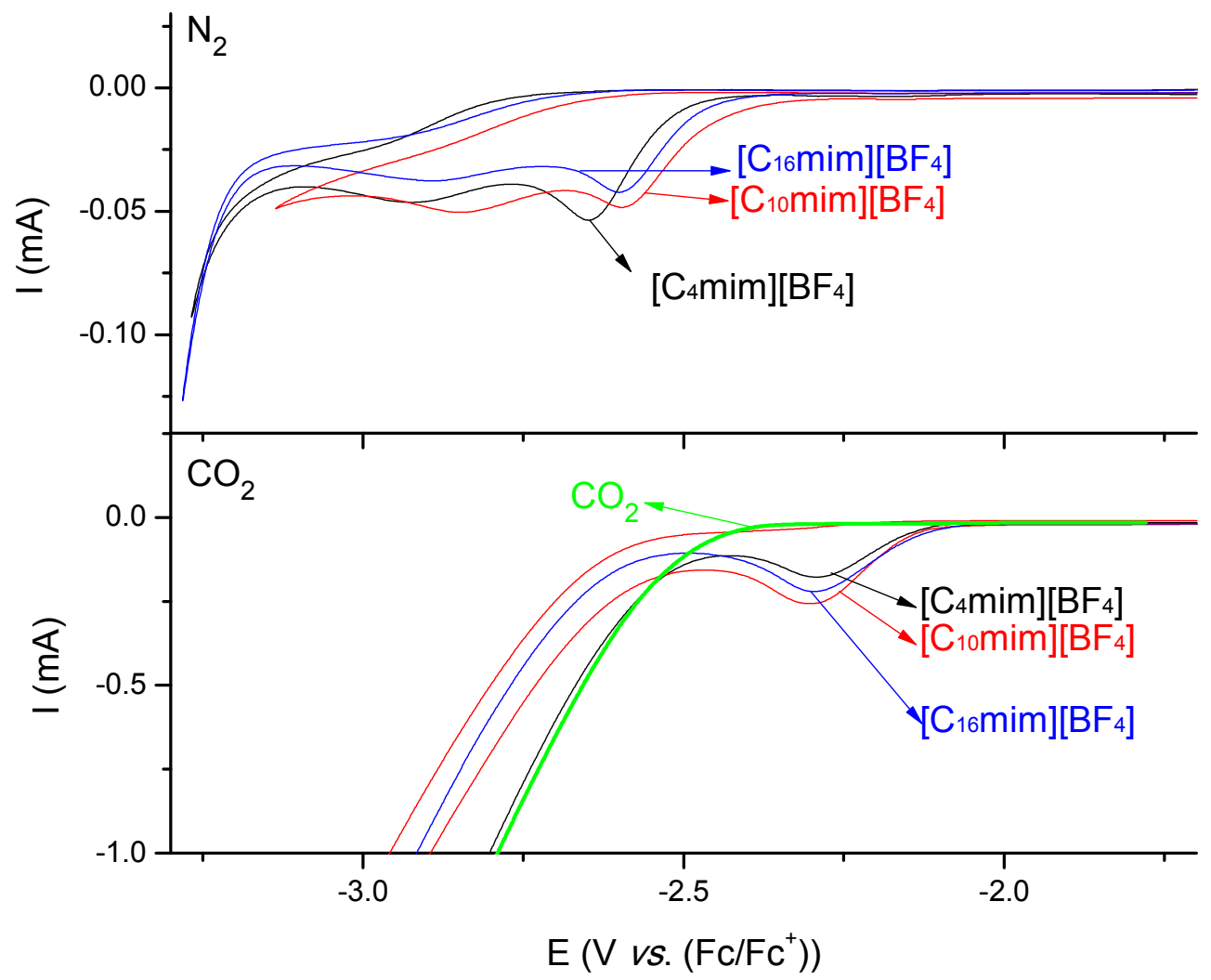

Figure S2. Cyclic voltammograms obtained with a $3.0 \mathrm{~mm}$ diameter Ag electrode at a scan rate of $0.1 \mathrm{~V} \mathrm{~s}^{-1}$ in $\mathrm{MeCN}\left(0.1 \mathrm{M} \mathrm{n}-\mathrm{Bu}_{4} \mathrm{NPF}_{6}\right)$ containing $2.0 \mathrm{mM}\left[\mathrm{C}_{4} \mathrm{mim}\right]\left[\mathrm{BF}_{4}\right](-)$, $\left[\mathrm{C}_{10} \mathrm{mim}\right]\left[\mathrm{BF}_{4}\right](-)$ and $\left[\mathrm{C}_{16} \mathrm{mim}\right]\left[\mathrm{BF}_{4}\right](-)$ under $\mathrm{N}_{2}$ and $\mathrm{CO}_{2}$ atmospheres. Cyclic voltammogram of $\mathrm{CO}_{2}(-)$ in $\mathrm{MeCN}\left(0.1 \mathrm{M} n-\mathrm{Bu}_{4} \mathrm{NPF}_{6}\right)$ under the same conditions. 


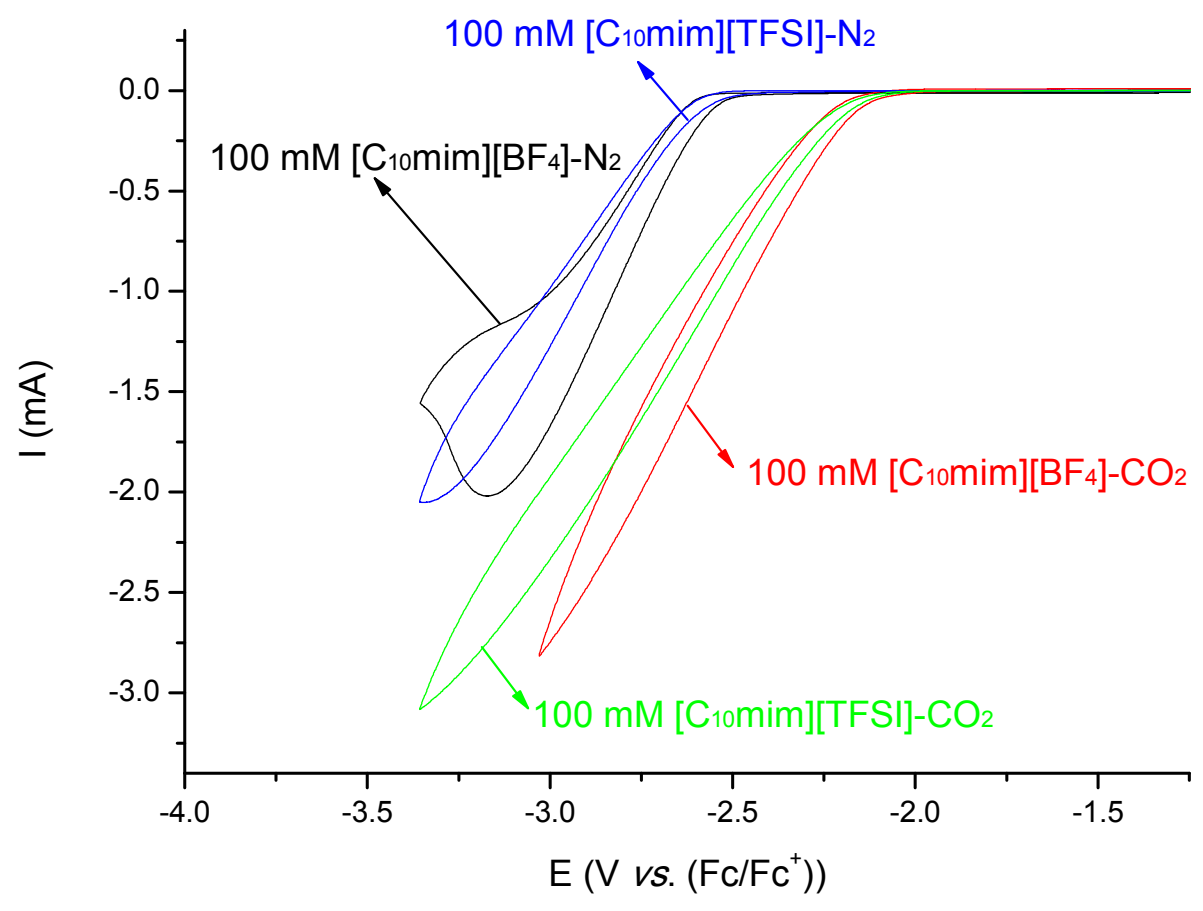

Figure S3. Cyclic voltammograms obtained with a $3.0 \mathrm{~mm}$ diameter Ag electrode with a scan rate of $0.1 \mathrm{~V} \mathrm{~s}^{-1}$ in $\mathrm{MeCN}$ containing $100.0 \mathrm{mM}\left[\mathrm{C}_{10} \mathrm{mim}\right]\left[\mathrm{BF}_{4}\right]$ or $\left[\mathrm{C}_{10} \mathrm{mim}\right][\mathrm{TFSI}]$ under $\mathrm{N}_{2}$ and $\mathrm{CO}_{2}$ atmospheres. 


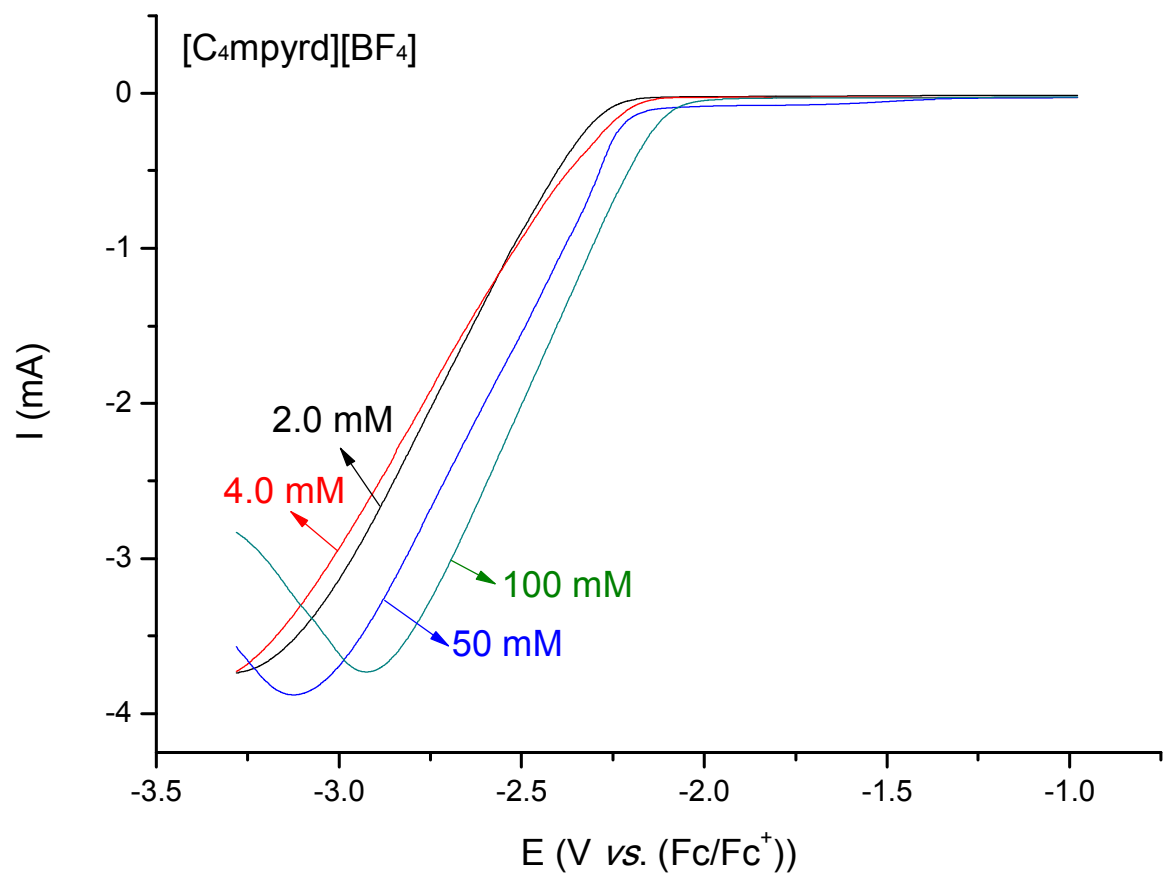

Figure S4. Cyclic voltammograms obtained at a $3.0 \mathrm{~mm}$ diameter Ag electrode with a scan rate of $0.1 \mathrm{~V} \mathrm{~s}^{-1}$ in $\mathrm{MeCN}\left(n-\mathrm{Bu}_{4} \mathrm{NPF}_{6}\right)$ under a $\mathrm{CO}_{2}$ atmosphere at a function of designated concentrations of $\left[\mathrm{C}_{4} \mathrm{mpyrd}\right]\left[\mathrm{BF}_{4}\right]: 2.0 \mathrm{mM}(-), 4.0 \mathrm{mM}(-), 50.0 \mathrm{mM}(-)$ and $100.0 \mathrm{mM}$ $(-)$. 


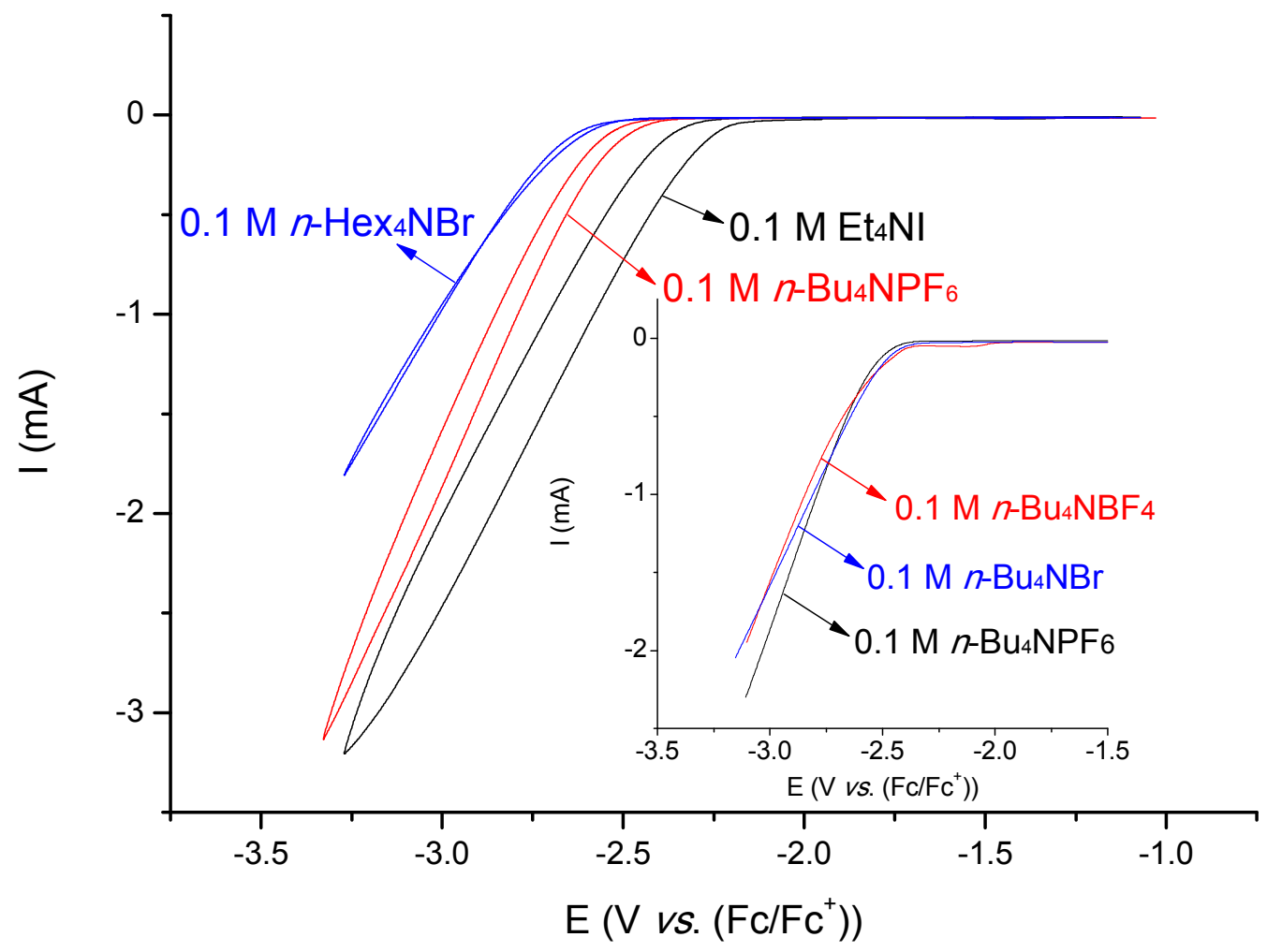

Figure S5. Cyclic voltammograms of $\mathrm{CO}_{2}$ obtained at a $3.0 \mathrm{~mm}$ diameter Ag electrode with a scan rate of $0.1 \mathrm{~V} \mathrm{~s}^{-1}$ in $\mathrm{MeCN}\left(0.1 \mathrm{M} n-\mathrm{Bu}_{4} \mathrm{NPF}_{6}\right)$ containing $0.1 \mathrm{M} \mathrm{Et}_{4} \mathrm{NI}(-), n-\mathrm{Bu}_{4} \mathrm{NPF}_{6}$ $(-)$ or $n-\mathrm{Hex}_{4} \mathrm{NBr}(-)$. Inset shows voltammograms under same conditions with $0.1 \mathrm{M} n$ $\mathrm{Bu}_{4} \mathrm{NPF}_{6}(-) ; n-\mathrm{Bu}_{4} \mathrm{NBr}(-)$ or $n-\mathrm{Bu}_{4} \mathrm{NBF}_{4}(-)$. 


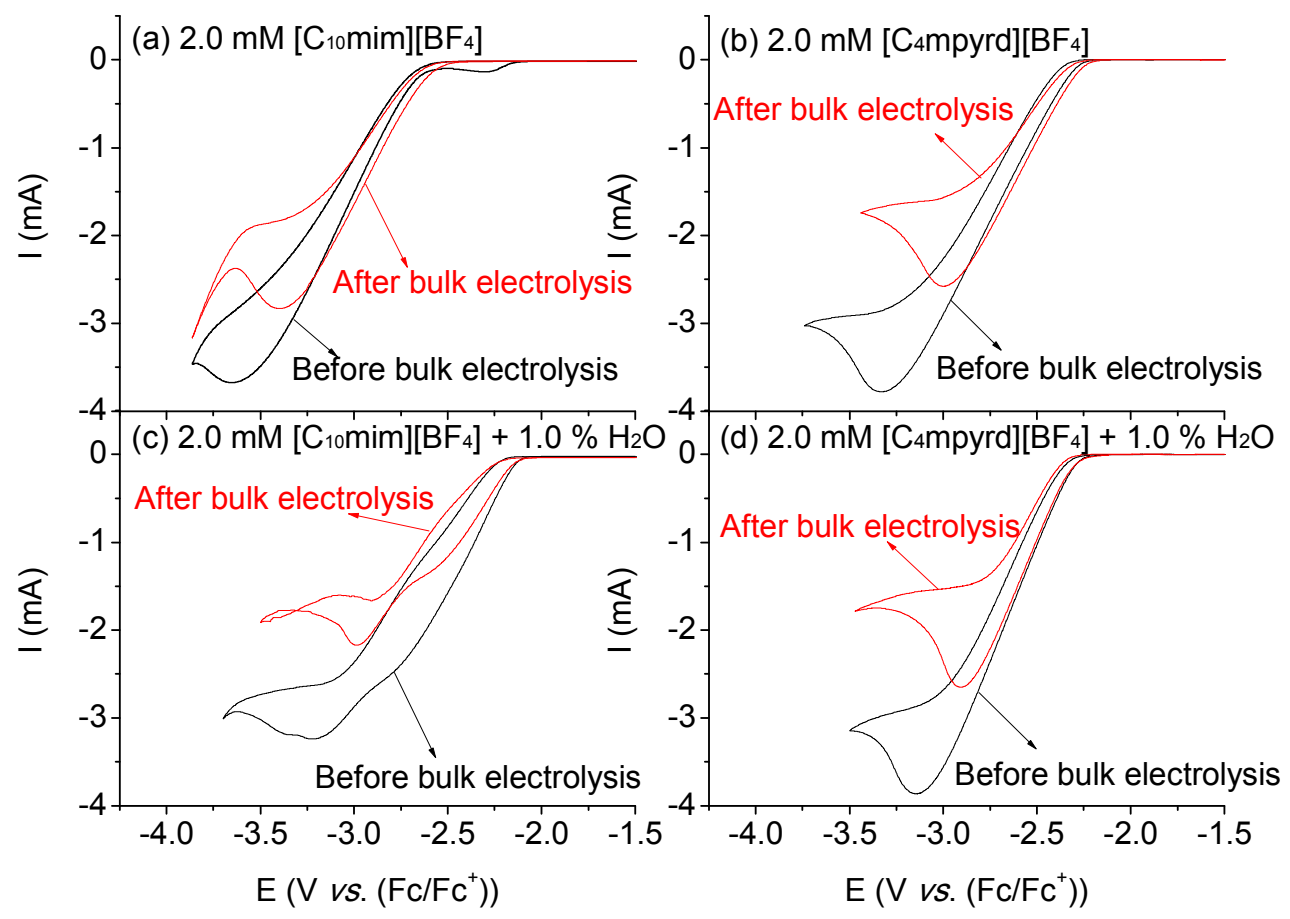

Figure S6. Cyclic voltammograms obtained at a $3.0 \mathrm{~mm}$ diameter Ag electrode with a scan rate of $0.1 \mathrm{~V} \mathrm{~s}^{-1}$ before $(-)$ and after bulk electrolysis $(-)$ in the presence of $2.0 \mathrm{mM}$ $\left[\mathrm{C}_{10} \operatorname{mim}\right]\left[\mathrm{BF}_{4}\right]$ (a and $\mathrm{c}$ ) or $\left[\mathrm{C}_{4} \mathrm{mpyrd}\right]\left[\mathrm{BF}_{4}\right]$ (b and d) with no deliberately added water or $1.0 \%$ added water in $\mathrm{MeCN}\left(0.1 \mathrm{M} n-\mathrm{Bu}_{4} \mathrm{NPF}_{6}\right)$ under a $\mathrm{CO}_{2}$ atmosphere. 